\title{
The inflammatory changes of adipose tissue in late pregnant mice
}

\author{
Lingyun Zhang, Takashi Sugiyama, Nao Murabayashi, Takashi Umekawa, \\ Ning $\mathrm{Ma}^{1}$, Yuki Kamimoto, Yoshihiro Ogawa ${ }^{2}$ and Norimasa Sagawa \\ Departments of Obstetrics and Gynecology, Mie University Graduate School of Medicine, 2-174 Edobashi, Tsu, Mie 514-8507, Japan \\ ${ }^{1}$ Faculty of Health Science, Suzuka University of Medical Science, Suzuka, Japan \\ ${ }^{2}$ Department of Molecular Medicine and Metabolism, Medical Research Institute, Tokyo Medical and Dental University, Tokyo, Japan \\ (Correspondence should be addressed to T Sugiyama; Email: tak-s @ clin.medic.mie-u.ac.jp)
}

\begin{abstract}
The infiltration of classically activated macrophages (M1) and alternatively activated macrophages (M2) in subcutaneous adipose tissue (SAT) and parametrial adipose tissue (PAT) was analyzed to investigate whether local inflammatory change in adipose tissue occurs in late pregnancy. C57BL/6N female mice at 6 weeks of age were fed a normal chow diet for 4 weeks prior to mating at 10 weeks of age and were sampled on day 17 of pregnancy. The serum levels of adipokines and biochemical markers were measured using ELISA and enzymatic methods. The identification of M1 and M2 was analyzed by double immunofluorescence with anti-F4/80 and anti-CD11c antibodies. The gene expression of adipokines in adipose tissues was analyzed by quantitative RT-PCR. The pregnant group showed adipocyte hypertrophy, higher macrophage infiltration, and higher M1/M2 in both SAT and PAT compared with the non-pregnant (NP) group. Serum levels of free fatty acids, tumor necrosis factor $\alpha$ (TNF $\alpha$ ), interleukin 6 (IL6), and IL10 were higher, and serum levels of adiponectin were lower in the pregnant group than those in the NP group. The gene expressions of CD68, Itgax, CCR2, $T N F \alpha$, and $P A / 1$ in SAT during pregnancy were significantly higher than those in the NP group, as were the gene expressions of $C D 68$, Emrl, Itgax, MCP1, TNF $\alpha$, IL6, PAl1, adiponectin, and IL10 in PAT. These results suggest that the low-grade inflammation of adipose tissue indicated by increased macrophage infiltration occurs in late normal pregnancy.

Journal of Molecular Endocrinology (2011) 47, 157-165
\end{abstract}

\section{Introduction}

A chronic low-grade inflammatory state of adipose tissue has been implicated in the development of insulin resistance in non-pregnant (NP) obese subjects (Weisberg et al. 2003, Xu et al. 2003). Adipocytes in obesity increase triglyceride accumulation, resulting in hypertrophy and adipose tissue remodeling. Hypertrophied adipocytes release monocyte chemoattractant protein 1 (MCP1; Kanda et al. 2006), which activates blood monocytes through CC chemokine receptor 2 (CCR2) and induces monocyte migration to adipose tissue and differentiation into macrophages. CCR2 also plays a key role in monocyte/macrophage recruitment and macrophage-dependent inflammatory response (Boring et al. 1998). Mouse models demonstrated that accumulation of macrophages into adipose tissue via the MCP1/CCR2 pathway is necessary for the development of insulin resistance related to obesity (Weisberg et al. 2006). Although it has been reported that hypertrophy of adipocyte results in late pregnancy (Kondo et al. 2004), little is known about whether such an inflammatory change actually occurs.

Macrophages in adipose tissue are activated in response to free fatty acids (FFA), whereby they are released from hypertrophied or dead adipocytes, producing larger amounts of inflammatory factors such as tumor necrosis factor $\alpha(\mathrm{TNF} \alpha)$, interleukin 6 (IL6), plasminogen activator inhibitor type 1 (PAI1), MCP1, and others, which, in turn, augment the release of FFA and inflammatory changes in adipocytes (Suganami et al. 2005). In addition, macrophagederived MCP1 further induces blood monocytes to differentiate macrophages and recruits them into adipose tissue, establishing a vicious cycle that aggravates inflammatory changes in NP obese adipose tissue. Accumulation of macrophages in adipose tissue seems to be a feature characteristic to expanding adipose tissue.

A recent study has shown that different stimuli activate macrophages in adipose tissue to express distinct patterns of chemokines, surface markers, and metabolic enzymes that ultimately generate the diversity of macrophage function seen in inflammatory and non-inflammatory settings, and macrophages in adipose activation have been operationally defined into separate polarization stats, M1 and M2 (Lumeng et al. 2007). The M1 macrophages produce TNF $\alpha$, IL6, and nitric oxide. In contrast, the M2 macrophages produce anti-inflammatory cytokines 
IL10 and arginase (Kawanishi et al. 2010). Fujisaka et al. (2011) used microarray analysis to demonstrate that the M1 macrophage markers include CD11c, TNF $\alpha$, IL6, and MCP1, and the M2 macrophage marker is IL10.

We previously reported that the weight of adipose tissue physiologically increases during pregnancy (Kondo et al. 2004). However, whether the physiological increase in adipose tissue during pregnancy accompanies an increase in macrophage infiltration into adipose tissue and whether the inflammatory changes of adipose tissue exist in late pregnancy are factors that remain unexplained.

A hypothesis of this study was that a low-grade inflammatory status in adipose tissue occurs in late pregnancy, including accumulation of M1 macrophages in the adipose tissue, as well as in NP obese subjects. To demonstrate whether the inflammatory change in adipose tissue also occurs in late pregnancy, pregnant mice were used to examine adipocyte size, the changes in the infiltration of M1 and M2 macrophages, serum adipokine levels, and the gene expression of adipokines in subcutaneous adipose tissue (SAT) and parametrial adipose tissue (PAT).

\section{Materials and methods}

\section{Experimental animals and diets}

All experimental protocols with mice were approved by the Animal Ethics Committee of Mie University. Charles River (Osaka, Japan) supplied the 5-week-old C57BL/6N female mice. These mice were fed a normal chow diet $(10 \%$ energy from fat, $70 \%$ from carbohydrate, and $20 \%$ from protein; catalog no. D12450B; Research Diets, Inc., New Brunswick, NJ, USA) and were mated only once at 10 weeks of age. All mice were maintained under a $12 \mathrm{~h}$ light:12 h darkness cycle and had access to food and water ad libitum unless indicated. The presence of a plug was regarded as embryonic day 0 (E0). The mice that failed to achieve pregnancy were placed into the NP group. Finally, 32 control and 26 pregnant mice were used for the experiment. The body weight was measured daily. The mice were dissected at E17 after a 14-16 h fast. Dams with a litter size of 7-9 were included as experimental subjects in this study, i.e. pregnant group, and the remaining dams were redirected.

\section{Collection of blood and tissue samples}

The mice were killed at E17. Blood was collected, allowed to clot, and spun at $800 \mathrm{~g}$ to collect serum. The SAT and PAT were removed. Adipose tissues were fixed in $4 \%$ paraformaldehyde (Nakarai Tesque,
Kyoto, Japan), and the other tissues were frozen in liquid nitrogen and stored at $-80^{\circ} \mathrm{C}$ prior to RNA extraction.

\section{Metabolic testing}

For glucose tolerance test (GTT), the mice were deprived of food for 14-16 h overnight and then given peritoneal injections of glucose $(2 \mathrm{~g} / \mathrm{kg}$ body mass; Otsuka Pharmaceutical Co. Ltd, Tokusima, Japan) at E17. For insulin tolerance test (ITT), the mice were deprived of food for $3 \mathrm{~h}$ at E16 and then given peritoneal injections of human regular insulin $(0 \cdot 75 \mathrm{U} / \mathrm{kg}$ body mass; Eli Lilly and Co.). The mice that received ITT did not receive GTT. Thus, 32 control mice received either GTT $(n=17)$ or ITT $(n=15)$. A number (16) of the pregnant mice also received either GTT $(n=9)$ or ITT $(n=7)$. Blood samples were collected before and 15, 30, 60, and $120 \mathrm{~min}$ after injection, and plasma glucose was measured with a One Touch Ultra instrument (Lifescan, Inc., Tokyo, Japan).

\section{Analysis of metabolic parameters}

All serum measurements were made after fasting for one night. Serum FFA levels were measured using NEFA-C (Wako Pure Chemical Industries, Inc., Osaka, Japan). The serum concentrations of mouse MCP1, IL6, and IL10 were measured using ELISA kits (R\&D Systems, Minneapolis, MN, USA). The serum concentrations of mouse TNF $\alpha$ were measured using mouse TNF $\alpha$ ELISA Kits (Shibayagi Co. Ltd, Shibukawa, Japan). The serum adiponectin levels were measured using an adiponectin ELISA Kit (Otsuka Pharmaceutical Co. Ltd).

\section{Immunohistochemical study}

Adipose tissues were fixed in $4 \%$ paraformaldehyde in $0 \cdot 01 \mathrm{M}$ sodium PBS ( $\mathrm{pH} 7 \cdot 4$ ) for $14 \mathrm{~h}$ at $4{ }^{\circ} \mathrm{C}$. The fixed samples were embedded in paraffin (Merck Co. Ltd) and cut into $7 \mu \mathrm{m}$-thick sections. The sections were mounted on glass slides coated with triethoxyaminopropylsilane (Dako ChemMate, Kyoto, Japan).

Adipose sections were deparaffinized with xylene and rehydrated through graded concentrations of ethanol. The sections were stained with hematoxylin and eosin, adipocyte size was counted from ten fields on each section, and 50 adipocytes were counted from one field using WinRoof 5.7 Software (Mitani Corp., Fukui, Japan).

CD68 is known to be not only a typical phagocytic marker but also an indicator of macrophage number (Di Gregorio et al. 2005). Therefore, the definition of the macrophages was analyzed using anti-CD68 antibody. For antigen retrieval, deparaffinized sections 
were microwaved for $5 \mathrm{~min}$ in citric acid buffer $(\mathrm{pH} 6 \cdot 0)$. Tissue sections were quenched with peroxidase blocking solution $\left(1 \% \mathrm{H}_{2} \mathrm{O}_{2}\right)$ for $15 \mathrm{~min}$ and blocked with $1 \%$ normal goat serum for $30 \mathrm{~min}$. Tissue sections were incubated overnight with mouse antiCD68 monoclonal antibody (1:50, Imgenex Corp., San Diego, CA, USA). The sections were incubated with anti-mouse IgG-HRP (1:200, Medical \& Biological Laboratories Co. Ltd, Nagoya, Japan) for $3 \mathrm{~h}$ after washing. The reaction product was visualized by incubation with $\mathrm{DAB}$ substrate chromogen and immersed in distilled water. Tissue sections were counterstained with hematoxylin for $2 \mathrm{~min}$ and rinsed with distilled water, dehydrated by sequential immersion in gradient ethanol and xylene, then mounted with Entellan New (Merck KGaA), and coverslipped. To evaluate the degree of infiltration by macrophages, adipocytes and macrophages were counted from 30 fields on each section, with macrophages expressed as percentage of the total adipocytes counted.

The definition of the macrophage subtypes was assessed using a double immunofluorescence labeling study. Briefly, sections were incubated for $60 \mathrm{~h}$ with rat monoclonal anti-F4/80 antibody (1:50, Santa Cruz Biotechnology, Inc., Santa Cruz, CA, USA) and hamster monoclonal anti-CD11c (1:25, AbD Serotec, Kidlington, UK). Alexa 594-labeled antibody against rat IgG and IgM antibodies and Alexa 488-labeled goat antibody against hamster IgG antibody (1:400, Molecular Probes, Inc., Eugene, OR, USA) were incubated for $3 \mathrm{~h}$. The stained sections were examined under an inverted laser scan microscope (Fluoview FV1000, Olympus, Tokyo, Japan). Tissue sections were mounted with Thermo (Thermo Fisher Scientific Anatomical Pathology, Kalamazoo, MI, USA) and coverslipped. A number (6) of specimens were randomly selected from each group, NP and pregnant, and then the number of cells was counted per microscopic field. F4/80 is a marker of mature macrophages (Kanda et al. 2006). CD11c is a M1 macrophage-specific marker, and $\mathrm{F} 4 / 80^{+} \mathrm{CD} 11 \mathrm{c}^{+}$cells in adipose tissue are known to be a specific population of macrophages recruited to adipose tissue that subsequently overexpress inflammatory genes like M1 macrophages (Lumeng et al. 2007, Fujisaka et al. 2011). Therefore, cells in which both F4/80 and CD11c were positive were regarded as M1 macrophages, and the cells that were F4/80 positive and $\mathrm{CD} 11 \mathrm{c}$ negative were regarded as M2 macrophages. However, we cannot clearly distinguish between M1 macrophages and M2 macrophages by this method.

\section{RNA isolation, RT-PCR, and quantitative real-time PCR}

Total RNA was extracted from adipose tissues with the use of a Sepasol-RNA1 Super according to the
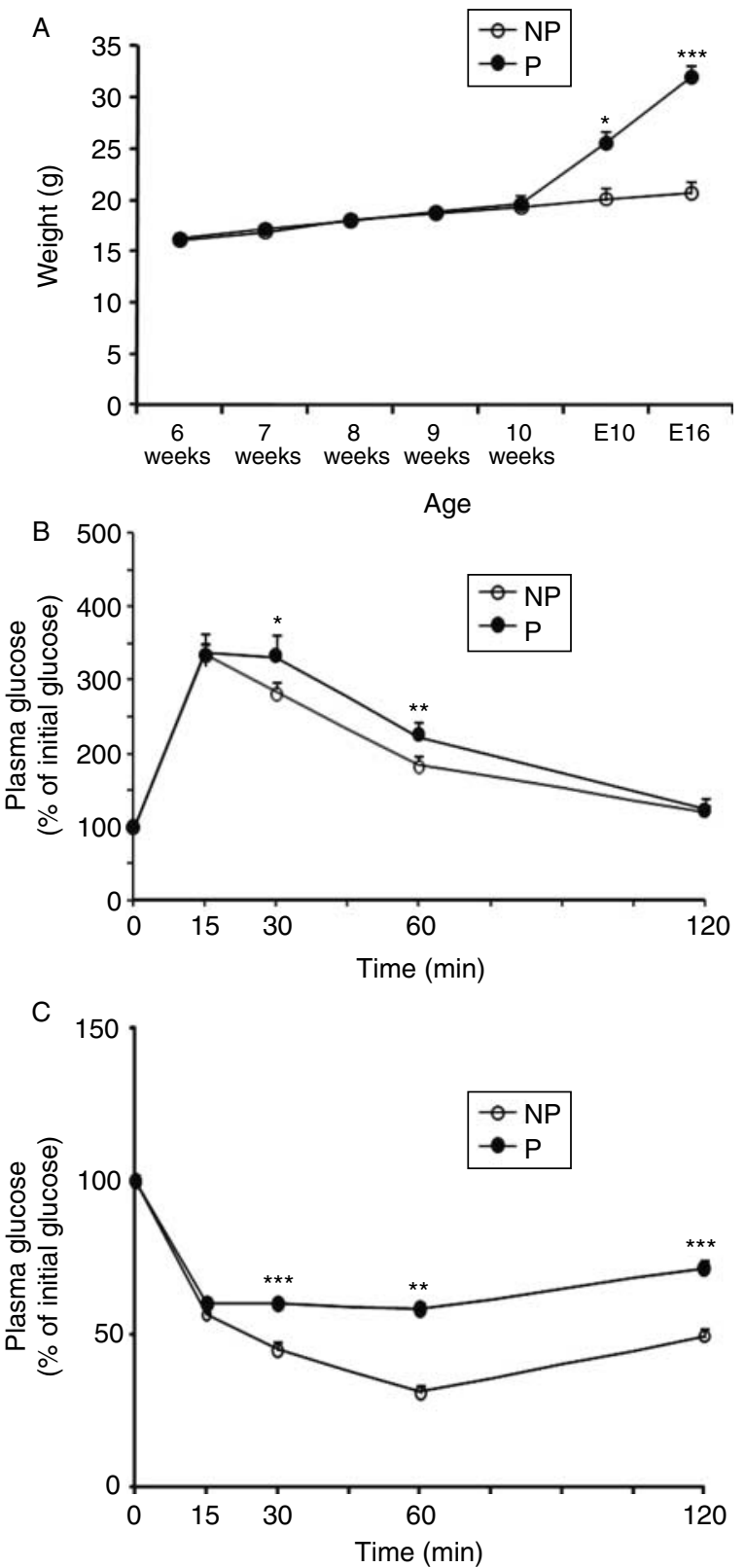

Figure 1 Comparison of body weight and metabolic profiles between the $P$ group and the NP group. (A) Changes in body weight of the NP group $(n=32)$ and the P group $(n=26)$ before and during pregnancy. E10, embryonic day 10; E16, embryonic day 16. (B) Circulating glucose levels were measured during a glucose tolerance test (NP, $n=17 ; \mathrm{P}, n=9$ ). GTT points were normalized to the baseline glucose levels at 0 min. (C) Plasma glucose level during the insulin tolerance test (NP, $n=15 ; \mathrm{P}, n=7$ ). ITT points were normalized to the baseline glucose levels at $0 \mathrm{~min}$. Data are presented as the mean \pm S.E.M. For body weight, a two-tail Student's $t$-test was performed, and two-way ANOVA was performed for glucose and insulin tolerance. $P$ versus NP: ${ }^{\star} P<0.05,{ }^{\star \star} P<0.01,{ }^{\star \star \star} P<0.001$. 
manufacturer's instructions (Nakarai Tesque), and portions $(10-15 \mu \mathrm{g})$ of the isolated RNA were subjected to real-time quantitative PCR analysis. Gene expression was quantified as a two-step RT-PCR. cDNA synthesized from total RNA was analyzed using TaqMan reverse transcription reagents and a TaqMan Gold RT-PCR Kit (Applied Biosystems, Carlsbad, CA, USA) according to the manufacturer's instructions. All PCRs were performed using a real-time PCR 7300 system with specific primers and a PCR Master Mix (Applied
Biosystems). Assays were performed in $50 \mu \mathrm{l}$ of singleplex reaction mixture. Reaction conditions consisted of pre-incubation at $50^{\circ} \mathrm{C}$ for $2 \mathrm{~min}$ and $95^{\circ} \mathrm{C}$ for $10 \mathrm{~min}$, followed by 40 cycles of $95^{\circ} \mathrm{C}$ for $15 \mathrm{~s}$ and $60^{\circ} \mathrm{C}$ for $1 \mathrm{~min}$. The concentration values were automatically recorded. Quantitative RT-PCR data are presented as the mean \pm s.E.M. (arbitrary units).

The relative abundance of mRNAs was calculated with $G A P D H(20 \times, 4352932 \mathrm{E})$ as the internal control. The target genes were as follows: mouse CD68
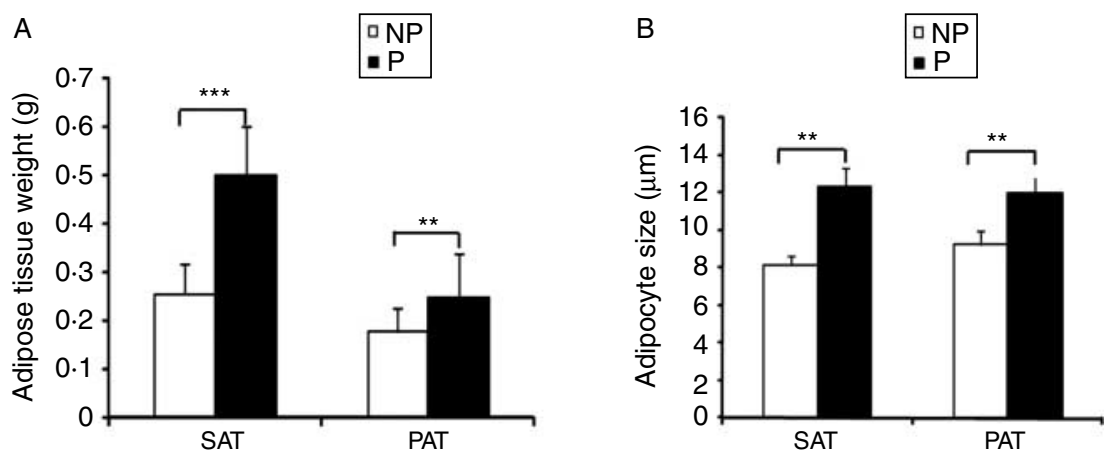

C

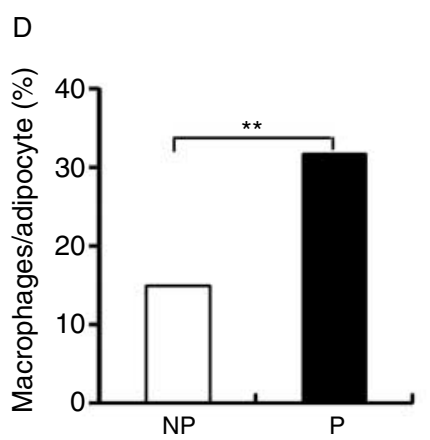

E
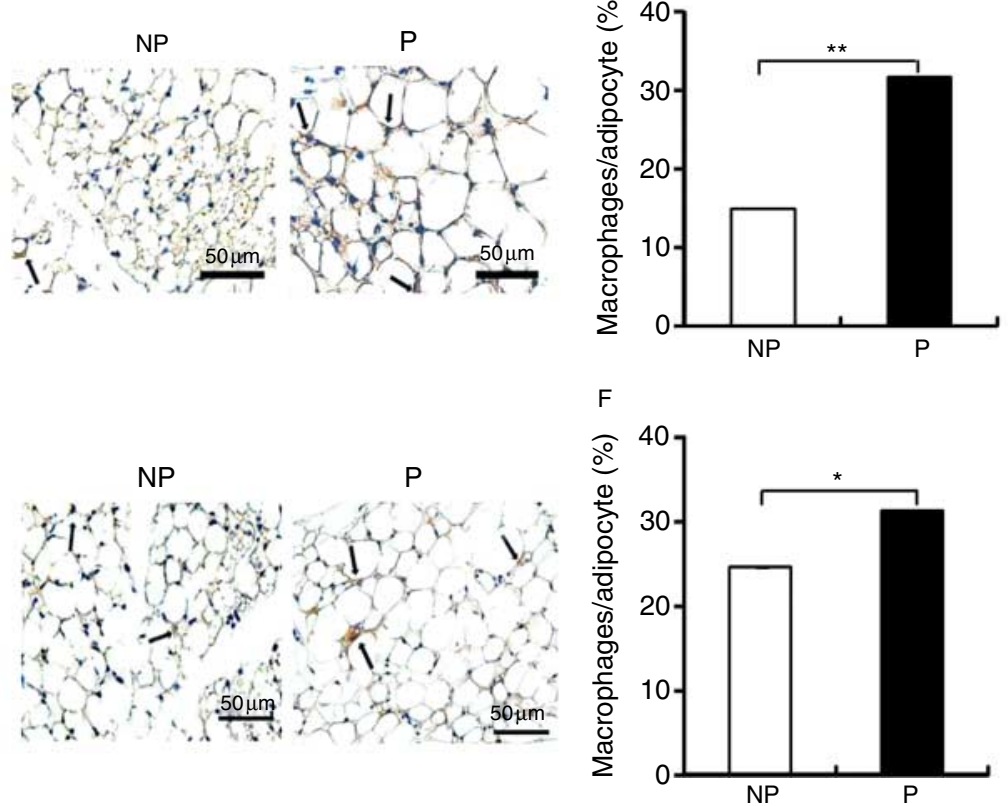

Figure 2 The effect of pregnancy on adipose tissue weight, adipocyte hypertrophy, and macrophage infiltration. (A) Weight of subcutaneous and parametrial adipose tissue of the NP group $(n=32)$ and the P group $(n=26)$. (B) Adipocyte size of subcutaneous and parametrial adipose tissue was measured using WinRoof 5.7 ( $n=6$ per group). (C) The infiltration of macrophages into SAT was revealed by immunohistochemical study using anti-CD68 antibody ( $n=6$ per group). (D) Quantitative analysis of the degree of macrophages infiltrated into SAT ( $n=6$ per group). (E) Immunohistochemical localization of CD68-positive macrophages in PAT ( $n=6$ per group). (F) Quantitative analysis of the degree of macrophages infiltrated into PAT ( $n=6$ per group). Data are presented as the mean \pm S.E.M. The two-tail Student's $t$-test was performed. $P$ versus NP: ${ }^{*} P<0 \cdot 05$, ${ }^{\star \star} P<0.01,{ }^{\star \star \star} P<0.001$. 
(Mm00839636_ml), Emrl (Mm00802529_ml, encoding F4/80), Itgax (Mm00498698_ml, encoding CD11c), MCP1 (Mm00441242_ml), CCR2 (Mm99999051_ml), TNFa (Mm00443258_ml), IL6 (Mm00446190_ml), PAI1 (Mm00436753_ml), adiponectin (Mm456425_ml), and IL10 (Mm0043616_ml).

\section{Statistical analysis}

Results are shown as the mean \pm s.E.M. Statistical analysis was performed using the SPSS 11.0 Software (SPSS Inc., Chicago, IL, USA). The two-way ANOVA was performed for GTT and ITT and the two-tail Student's $t$-test was performed for the others. Significance was considered to be $P<0 \cdot 05$.

\section{Results}

\section{Comparing the NP and the pregnant groups for body weight and glucose and insulin tolerance}

The body weight of the NP group was the same as that of the pregnant group before mating. However, the body weight in the pregnant group was significantly heavier than that in the NP group during pregnancy $(18 \cdot 3 \pm 2 \cdot 6$ vs $29 \cdot 7 \pm 1 \cdot 3 \mathrm{~g}, P=0 \cdot 0001$; Fig. $1 \mathrm{~A})$.

GTT was performed to compare glucose tolerance between the pregnant group and the NP group. The results are shown in Fig. 1B. A deterioration was detected in glucose tolerance during GTT at 30 and $60 \mathrm{~min}(30 \mathrm{~min}: \mathrm{F}(1 \cdot 25)=4.93, P=0.04 ; 60 \mathrm{~min}$ : $\mathrm{F}(1 \cdot 25)=11 \cdot 2, P=0 \cdot 003)$.

ITT was performed to evaluate the degree of insulin resistance. The percent reduction of glucose concentration in the pregnant group was significantly less than that in the NP group at 30,60 , and $120 \mathrm{~min}(30 \mathrm{~min}$ : $\mathrm{F}(1 \cdot 21)=17 \cdot 2, \quad P=0.0005 ; 60 \mathrm{~min}: \mathrm{F}(1 \cdot 21)=9 \cdot 46$, $P=0 \cdot 006 ; 120$ min: $\mathrm{F}(1 \cdot 21)=15 \cdot 9, P=0 \cdot 0007$; Fig. $1 \mathrm{C})$.

\section{Comparisons of the weight of adipose tissue, size of adipocytes, and degree of macrophage infiltration into adipose tissue between the NP and the pregnant groups}

The weight of adipose tissue for both SAT and PAT was significantly higher in the pregnant group than that in the NP group (SAT: $0 \cdot 26 \pm 0 \cdot 04$ vs $0 \cdot 50 \pm 0 \cdot 02 \mathrm{~g}, P=0 \cdot 0001$ and PAT: $0 \cdot 18 \pm 0 \cdot 02$ vs $0 \cdot 25 \pm 0 \cdot 02 \mathrm{~g}, P=0 \cdot 008$; Fig. 2A).

The sizes of adipocytes were measured using sections stained with hematoxylin and eosin, using the WinRoof 5.7 Software. The sizes of adipocytes in both SAT and PAT were significantly greater in the pregnant group than those in the NP group (SAT: $8 \cdot 20 \pm 0 \cdot 89$ vs $12 \cdot 09$ $\pm 2 \cdot 36 \mu \mathrm{m}, P=0 \cdot 003$; PAT: $9 \cdot 29 \pm 1 \cdot 36$ vs $11.58 \pm 0 \cdot 20 \mu \mathrm{m}$, $P=0 \cdot 003$; Fig. 2B).
Macrophage infiltration in the pregnant group increased 2.1-fold in SAT (Fig. 2C and D) and increased 1.4-fold in PAT (Fig. 2E and F) compared with that in the NP group (SAT: $31 \cdot 84 \pm 2 \cdot 04$ vs $15 \cdot 1 \pm 1.57 \%$, $P=0 \cdot 002$; PAT: $31 \cdot 5 \pm 2 \cdot 45$ vs $22 \cdot 86 \pm 1 \cdot 84 \%, P=0 \cdot 027)$.

\section{Serum measurements}

Serum FFA levels in the pregnant group significantly increased compared with those in the NP group (1.06 \pm 0.08 vs $0.65 \pm 0.05 \mathrm{mEq} / 1, \quad P=0.001$; Fig. $3 \mathrm{~A})$. Serum MCP1 levels showed no significant difference between the pregnant group and the NP group $(39 \cdot 40 \pm 6 \cdot 13$ vs $33 \cdot 25 \pm 3 \cdot 87 \mathrm{pg} / \mathrm{ml}, P=0 \cdot 24$; Fig. 3B). Serum levels of TNF $\alpha$ and IL6 in the pregnant group increased compared with those in the NP group (TNF $\alpha$ : $112.97 \pm 10.60$ vs $34.41 \pm 6.66 \mathrm{pg} / \mathrm{ml}, P=0.0001$; IL6: $26 \cdot 79 \pm 6 \cdot 02$ vs $9 \cdot 90 \pm 1 \cdot 24 \mathrm{pg} / \mathrm{ml}, P=0 \cdot 037$; Fig. $3 \mathrm{C}$ and D). Serum levels of IL10 in the pregnant group significantly increased compared with those in
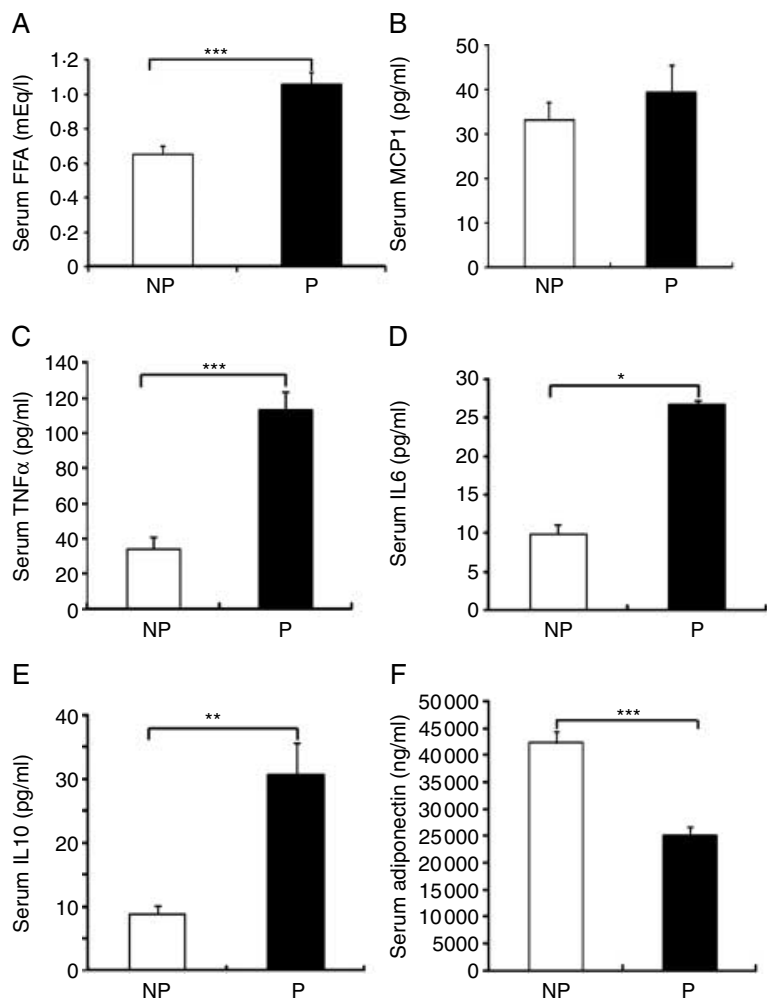

Figure 3 Serum measurements between the $P$ group and the NP group. (A) Serum fasting FFA levels of the NP group $(n=6)$ and the $P$ group $(n=7)$. (B) Serum MCP1 levels of the NP group $(n=10)$ and the P group $(n=9)$. (C) Serum TNF $\alpha$ levels of the NP group $(n=11)$ and the P group $(n=7)$. (D) Serum IL6 levels of the NP group $(n=9)$ and the P group $(n=10)$. (E) Serum IL10 levels of the NP group $(n=9)$ and the $\mathrm{P}$ group $(n=11)$. (F) Serum adiponectin levels of the NP group $(n=10)$ and the P group $(n=8)$. Data are presented as the mean \pm S.E.M. A two-tail Student's $t$-test was performed. $P$ versus NP: ${ }^{\star} P<0.05,{ }^{\star *} P<0.01,{ }^{\star \star \star} P<0.001$. 
the NP group (IL10: $30.74 \pm 4.89$ vs $8.93 \pm 1.42 \mathrm{pg} / \mathrm{ml}$, $P=0.002$; Fig. 3E). Serum adiponectin levels in the pregnant group decreased $40 \%$ compared with those in the NP group (adiponectin: $25098 \cdot 01 \pm 1319.73$ vs $42310 \cdot 66 \pm 2153 \cdot 16 \mathrm{ng} / \mathrm{ml}, P=0 \cdot 0001$; Fig. $3 \mathrm{~F}$ ).

\section{The immunohistochemical analyses of macrophage subtypes in adipose tissue}

To assess the changes between M1 and M2 macrophages, double immunofluorescence staining with anti-F4/80 antibody and anti-CD11c antibody was performed. The M1/M2 ratio in the pregnant group displayed a 6.5-fold increase in SAT (Fig. 4A and B) and a $7 \cdot 0$-fold increase in PAT (Fig. 4C and D) compared with that in the NP group (SAT: $3 \cdot 69 \pm 0.57$ vs $0.41 \pm 0.09$, $P=0 \cdot 0002$; PAT: $5 \cdot 68 \pm 0 \cdot 86$ vs $0 \cdot 81 \pm 0 \cdot 09, P=0 \cdot 0002$ ).

\section{The gene expression of adipokines in adipose tissue}

Gene expression was investigated as it is related to macrophage function. CD68 is known to be a macrophage marker for phagocytosis. The pregnant group showed a significant increase in both SAT and PAT compared with the NP group (SAT: $P=0.017$; PAT: $P=0.0001$; Fig. 5A). Compared with the NP group, $E m r l$ gene expression by the pregnant group was decreased by $50 \%$ in SAT and increased 4.7 -fold in PAT (SAT: $P=0 \cdot 047$; PAT: $P=0 \cdot 0001$; Fig. $5 \mathrm{~B})$. CD11c is an indicator of macrophage subtype classification encoded by Itgax. Itgax mRNA levels in the pregnant group significantly increased in both SAT and PAT compared with those in the NP group (SAT: $P=0 \cdot 018$; PAT: $P=0 \cdot 02$; Fig. $5 \mathrm{C}$ ).

$M C P 1$ mRNA levels displayed no significant difference between the NP group and the pregnant group in SAT $(P=0.57)$. However, in PAT, the pregnant group markedly increased compared with the NP group $(P=0.0001$; Fig. 5D). CCR2 mRNA levels were significantly higher in the pregnant group compared with those in the NP group in SAT $(P=0 \cdot 046)$. However, in PAT, there was no significant difference between the two groups $(P=0 \cdot 92$; Fig. $5 \mathrm{E})$.

We assessed the gene expression of pro-inflammatory factors such as $T N F \alpha, I L 6$, and $P A I I$ and anti-inflammatory factors such as $I L 10$ and adiponectin. TNF $\alpha$ mRNA levels in the pregnant group significantly increased in both SAT and PAT compared with those in the NP group (SAT: $P=0 \cdot 004$; PAT: $P=0 \cdot 002$; Fig. $5 \mathrm{~F})$. The pregnant group increased IL6 gene expression in PAT $(P=0.036)$ compared with the NP group, but not SAT $(P=0 \cdot 83$; Fig. $5 \mathrm{G})$. The PAII mRNA levels in the pregnant group markedly increased in both SAT and PAT compared with those in the NP group (SAT: $P=0 \cdot 001$; PAT: $P=0 \cdot 002$; Fig. $5 \mathrm{H}$ ).
A

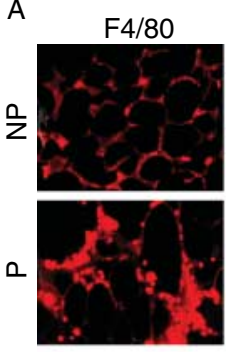

C
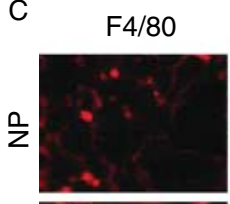

๑

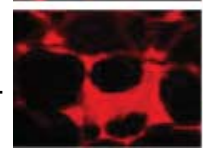

CD11c

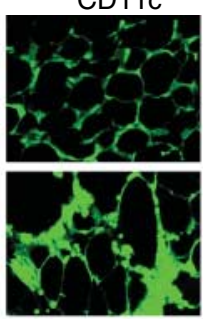

CD11c

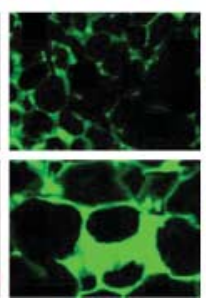

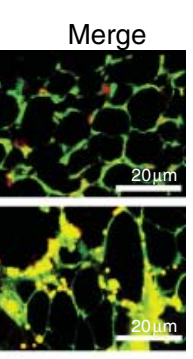

Merge

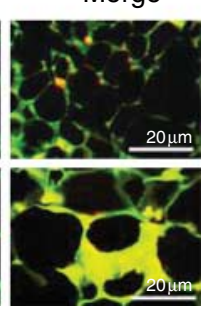

B

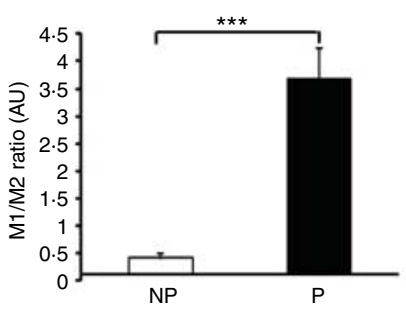

D

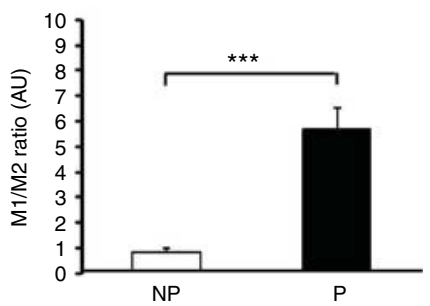

Figure 4 The definition of macrophage subtypes in adipose tissue from non-pregnant and pregnant mice. (A) Identification of $\mathrm{F} 4 / 80^{+} \mathrm{CD} 11 \mathrm{c}^{+}$macrophages by immunofluorescence microscopy in the frozen sections of SAT stained with antibodies against F4/80 (left) and CD11c (middle) and imaged by confocal microscopy to identify surface markers to confirm the presence of $\mathrm{CD} 11 \mathrm{c}^{+}$cells. $\mathrm{F} 4 / 80^{+} \mathrm{CD} 11 \mathrm{c}^{+}$macrophage: $\mathrm{M} 1$ macrophage; $\mathrm{F} 4 / 80^{-} \mathrm{CD}_{11 \mathrm{C}^{+}}$macrophage: $\mathrm{M} 2$ macrophage ( $n=6$ per group). (B) The ratio of M1-M2 macrophages in SAT ( $n=6$ per group). (C) Identification of $\mathrm{F} 4 / 80^{+}$and CD11c ${ }^{+}$ macrophages in PAT by immunofluorescence microscopy ( $n=6$ per group). (D) The ratio of M1-M2 macrophages in PAT ( $n=6$ per group). Data are presented as the mean \pm S.E.M. A two-tail Student's $t$-test was performed. $P$ versus NP: ${ }^{\star \star \star} P<0.001$. 


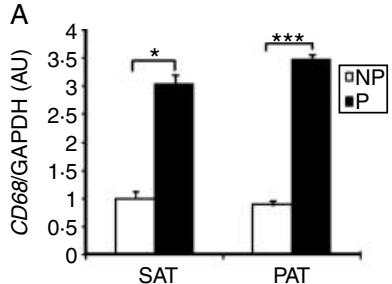

B
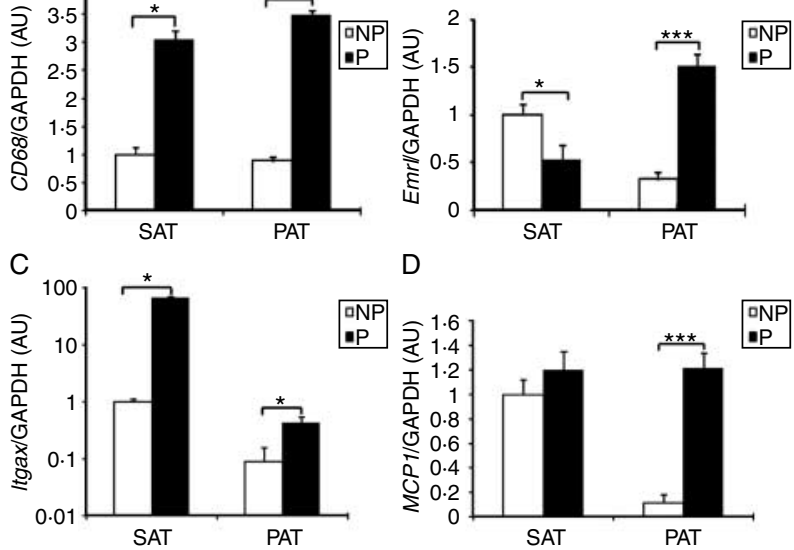

D
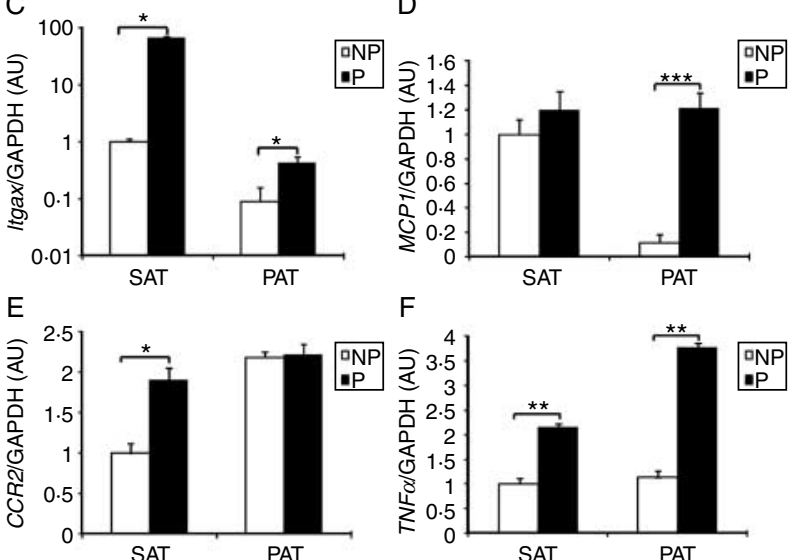

$\mathrm{F}$

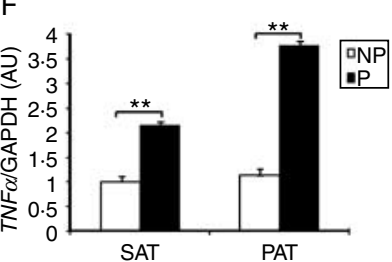

G

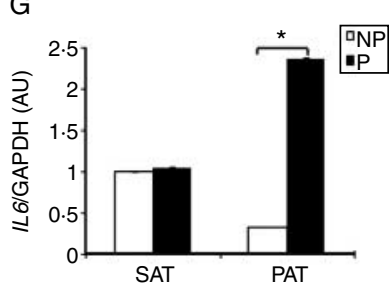

J
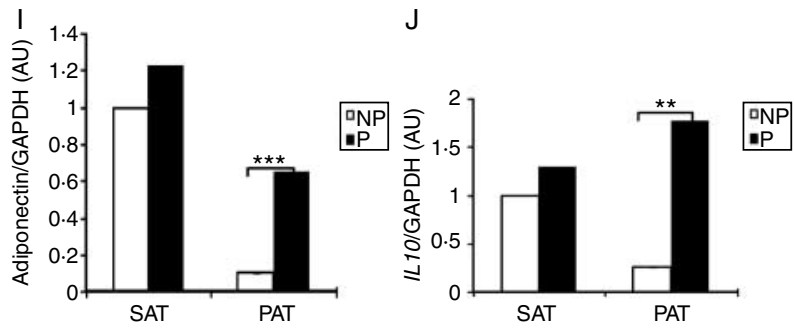

Figure 5 Gene expressions of inflammatory and anti-inflammatory adipokines in adipose tissue between the $\mathrm{P}$ group and the NP group. (A) CD68 gene expression of the NP group $(n=10)$ and the P group $(n=13)$. (B) Emrl gene expression of the NP group $(n=10)$ and the $\mathrm{P}$ group $(n=18)$. (C) Itgax gene expression of the NP group $(n=10)$ and the P group $(n=18)$. (D) MCP1 gene expression of the NP group $(n=8)$ and the P group $(n=12)$. (E) CCR2 gene expression of the NP group $(n=9)$ and the $\mathrm{P}$ group $(n=10)$. (F) TNF $\alpha$ gene expression of the NP group $(n=10)$ and the $P$ group $(n=17)$. (G) IL6 gene expression of the NP group $(n=6)$ and the $\mathrm{P}$ group $(n=8)$. $(\mathrm{H}) P A / 1$ gene expression of the NP group $(n=7)$ and the $\mathrm{P}$ group $(n=11)$. (I) Adiponectin gene expression of the NP group $(n=10)$ and the P group $(n=16)$.

(J) IL 10 gene expression of the NP group $(n=8)$ and the P group $(n=9)$. Macrophage-related adipokine gene expression was evaluated by real-time quantitative RT-PCR. Data are presented as the mean \pm S.E.M. A two-tail Student's $t$-test was performed.

$\mathrm{P}$ versus NP: ${ }^{\star} P<0.05,{ }^{\star \star} P<0.01,{ }^{\star \star \star} P<0.001$.
Adiponectin mRNA levels were significantly higher in the pregnant group compared with those in the NP group in PAT $(P=0 \cdot 0006)$, but not in SAT $(P=0 \cdot 56$; Fig. 5I). IL10 mRNA levels showed a tendency similar to adiponectin (PAT: $P=0 \cdot 0018$; SAT: $P=0 \cdot 21$; Fig. $5 \mathrm{~J}$ ).

\section{Discussion}

In this study, the pregnant mice model displayed glucose intolerance and insulin resistance, which was also demonstrated in previous reports (Hemmeryckx et al. 2008, Petry et al. 2010). In late pregnancy, we previously showed that the diameter of parametrial adipocytes increases 1-2-fold in mice compared with NP mice (Kondo et al. 2004). In this study, the size of subcutaneous adipocytes and parametrial adipocytes was 1.4- and 1.3-fold more, respectively, than that of the control subject. Adipocyte hypertrophy is reportedly related to macrophage infiltration of adipose tissue (Constant et al. 2006, Permana et al. 2006). Therefore, we examined whether inflammatory changes in adipose tissue occur in late pregnancy and found that inflammatory changes are in fact induced by macrophage infiltration in adipose tissue in late pregnancy.

This study showed that the pregnant mice model displayed the infiltration of macrophages into adipose tissue with an increase in the M1/M2 ratio for both SAT and PAT, suggesting that the inflammatory changes occur in adipose tissue in late pregnancy (Figs 2 and 4). These inflammatory changes are similar to those in NP obese subjects (Fujisaka et al. 2009). The gene expression of pro-inflammatory adipokines such as TNFo, IL6, and PAI1 significantly increased, and the anti-inflammatory adipokine IL10 also significantly increased (Fig. 5), which is consistent with NP obese subjects (Weisberg et al. 2003, Xu et al. 2003, Kanda et al. 2006, Strissel et al. 2007). However, the serum levels of FFA, TNF $\alpha$, IL6, and IL10 increased and adiponectin decreased (Fig. 3). These results suggest that the inflammatory changes occur during pregnancy not only in the adipose tissue but also at the systemic level. Also, these results are consistent with the hypothesis of this study, which states that increased M1 macrophage recruitment to adipose tissue causes an increase in the gene expression of proinflammatory adipokines such as TNF $\alpha$ and IL6, which leads to secretion into the blood, and contributes to the inflammatory changes in late pregnancy.

MCP1 is known to be a key initiator of macrophage infiltration into adipose tissue, so that changes to MCP1 and to its receptor, CCR2, are important. Although serum levels of MCP1 were not increased in the pregnant group in this study, MCP1 mRNA levels in pregnant PAT were higher than those in NP PAT. Also, although CCR2 mRNA levels in pregnant SATwere similar to those in NP SAT, there were no significant changes between 
pregnant and NP PAT. However, if the gene expression is adjusted by arbitrary units per total DNA of either SAT or PAT, mRNA levels of both MCP1 and CCR2 in pregnant SAT and PAT were higher than those in NP SAT and PAT respectively (data not shown). Taken together, these results are consistent with the theory that macrophage recruitment into adipose tissue is involved in the MCP1/CCR2 pathway in late pregnancy.

In the case of the NP obese mouse model, PAT is reportedly much more involved in pro-inflammatory changes compared with SAT (Weisberg et al. 2003, Okamoto et al. 2007). In this study, the PAT showed similar changes with the SAT. Therefore, the role of pro-inflammatory changes between SAT and PAT in late pregnancy is not yet clear, and further study is needed.

$\mathrm{TNF} \alpha$ is produced not only from monocytes and macrophages but also from T-cells, neutrophils, fibroblasts, and adipocytes (Barbour et al. 2007). This study revealed that the serum $T N F \alpha$ levels and $T N F \alpha$ gene expression in adipose tissue significantly increased in late pregnancy (Figs $3 \mathrm{C}$ and $5 \mathrm{~F}$ ). The serum $\mathrm{TNF} \alpha$ levels have been correlated to body mass index (BMI) or hyperinsulinemia in obese animals and humans (Hotamisligil \& Spiegelman 1994, Hotamisligil et al. 1996). Previous studies revealed that TNF $\alpha$ impaired insulin signaling by increasing serine phosphorylation of the insulin receptor substrate 1 (IRS1) and by diminishing insulin receptor tyrosine kinase activity (Hotamisligil \& Spiegelman 1994, Peraldi et al. 1996). Therefore, TNF $\alpha$ may be involved in insulin resistance in the present pregnant mice model.

IL6 underwent the same changes as TNF $\alpha$ at the serum and mRNA levels in this study. IL6 contributed to insulin resistance by impairing insulin signaling in the liver and in adipocytes and by inducing ubiquitinmediated degradation of the IRS1 through the suppression of cytokine signaling 1 (SOCS1) and SOCS3 (Emanuelli et al. 2000, Kristiansen \& Mandrup-Poulsen 2005). There was a different gene expression of IL6 between SAT and PAT in this study. However, when the gene expression was adjusted by arbitrary units per total DNA of either SAT or PAT, serum levels and gene expression of pro-inflammatory cytokines were almost consistent, and, therefore, serum levels of these factors reflected adipose tissue as the main source in this study. We cannot exclude the possibility that other sources such as placenta produce these cytokines.

The IL10 is an anti-inflammatory cytokine and is a critical effector molecule of M2 macrophages. The serum IL10 levels and the mRNA levels of IL10 were increased in pregnant subjects in this study, which was consistent with NP obese subjects (Strissel et al. 2007, Fujisaka et al. 2009). A previous study demonstrated that IL10 protected against TNF $\alpha$-dependent insulin resistance in adipocytes via activation of STAT3 (Lumeng et al. 2007) and modulated the transcription rates of inflammatory genes such as TNF and $M C P 1$ (Murray 2005). Therefore, IL10 may compensate for changes in M1-dominant adipokines during late pregnancy. However, there is a possibility that the increase in IL10 is caused by the increase in M2-related macrophages.

Serum adiponectin levels decreased in late pregnancy in this study, which was consistent with previous studies (Combs et al. 2003, Kondo et al. 2004). However, adiponectin gene expression increased in adipose tissue in the current study, which was inconsistent with previous reports on NP obesity (Arita et al. 1999, Cnop et al. 2003), leading to a possibility that adiponectin secretion was decreased in the present model. In fact, a posttranslational mechanism controlling adiponectin levels has been reported (Wang et al. 2007). Circulating levels of adiponectin have been shown to correlate with wholebody insulin resistance through adiponectin receptors in skeletal muscle and liver (Hara et al. 2005). From reports that TNF $\alpha$ and IL6 suppress the transcription of adiponectin in adipocytes (Bruun et al. 2003, Fasshauer et al. 2003), the increase in TNF $\alpha$ and IL6 serum levels and decrease in adiponectin serum levels in this study may be involved in insulin resistance in late pregnancy.

In this study, the imbalance between M1 and M2 macrophages induced by adipocyte hypertrophy broke the balance between inflammatory and anti-inflammatory adipokines, which eventually led to inflammatory changes of adipose tissue in late pregnancy. Inflammatory changes of adipose tissue may be involved in insulin resistance as a physiological adaptation to maintain maternal and fetal metabolism in late pregnancy.

\section{Declaration of interest}

The authors declare that there is no conflict of interest that could be perceived as prejudicing the impartiality of the research reported.

\section{Funding}

This research was supported in part by grants for Scientific Research from the Ministry of Education, Culture, Sports, Science, and Technology of Japan (No. 18659484, 19390428, and 22591821), the Smoking Research Foundation, and the Danone Institute of Japan.

\section{Acknowledgements}

We thank H Mastsuyama for her excellent technical assistance.

\section{References}

Arita Y, Kihara S, Ouchi N, Takahashi M, Maeda K, Miyagawa J, Hotta K, Shimomura I, Nakamura T, Miyaoka K et al. 1999 Paradoxical decrease of an adipose-specific protein, adiponectin, in obesity. Biochemical and Biophysical Research Communications 257 79-83. (doi:10.1006/bbrc.1999.0255) 
Barbour LA, McCurdy CE, Hernandez TL, Kirwan JP, Catalano PM \& Friedman JE 2007 Cellular mechanisms for insulin resistance in normal pregnancy and gestational diabetes. Diabetes Care 30 S1 12-S1 19. (doi:10.2337/dc07-s202)

Boring L, Gosling J, Cleary M \& Charo IF 1998 Decreased lesion formation in CCR2 $2^{-}-$mice reveals a role for chemokines in the initiation of atherosclerosis. Nature 394 894-897. (doi:10.1038/29788)

Bruun JM, Lihn AS, Verdich C, Pedersen SB, Toubro S, Astrup A \& Richelsen B 2003 Regulation of adiponectin by adipose tissue-derived cytokines: in vivo and in vitro investigations in humans. American Journal of Physiology. Endocrinology and Metabolism 285 E527-E533. (doi:10.1152/ajpendo.00110.2003)

Cnop M, Havel PJ, Utzschneider KM, Carr DB, Sinha MK, Boyko EJ, Retzlaff BM, Knopp RH, Brunzell JD \& Kahn SE 2003 Relationship of adiponectin to body fat distribution, insulin sensitivity and plasma lipoproteins: evidence for independent roles of age and sex. Diabetologia 46 459-469. (doi:10.1007/s00125-003-1074-z)

Combs TP, Berg AH, Rajala MW, Klebanov S, Iyengar P, JimenezChillaron JC, Patti ME, Klein SL, Weinstein RS \& Scherer PE 2003 Sexual differentiation, pregnancy, calorie restriction, and aging affect the adipocyte-specific secretory protein adiponectin. Diabetes 52 268-276. (doi:10.2337/diabetes.52.2.268)

Constant VA, Gagnon A, Landry A \& Sorisky A 2006 Macrophageconditioned medium inhibits the differentiation of 3T3-L1 and human abdominal preadipocytes. Diabetologia 49 1402-1411. (doi:10.1007/s00125-006-0253-0)

Di Gregorio GB, Yao-Borengasser A, Rasouli N, Varma V, Lu T, Miles LM, Ranganathan G, Peterson CA, McGehee RE \& Kern PA 2005 Expression of CD68 and macrophage chemoattractant protein-1 genes in human adipose and muscle tissues: association with cytokine expression, insulin resistance, and reduction by pioglitazone. Diabetes 54 2305-2313. (doi:10.2337/diabetes.54.8.2305)

Emanuelli B, Peraldi P, Filloux C, Sawka-Verhelle D, Hilton D \& Van Obberghen E 2000 SOCS-3 is an insulin-induced negative regulator of insulin signaling. Journal of Biological Chemistry $\mathbf{2 7 5}$ 15985-15991. (doi:10.1074/jbc.275.21.15985)

Fasshauer M, Kralisch S, Klier M, Lossner U, Bluher M, Klein J \& Paschke R 2003 Adiponectin gene expression and secretion is inhibited by interleukin-6 in 3T3-L1 adipocytes. Biochemical and Biophysical Research Communications 301 1045-1050. (doi:10.1016/S0006-291X(03)00090-1)

Fujisaka S, Usui I, Bukhari A, Ikutani M, Oya T, Kanatani Y, Tsuneyama K, Nagai Y, Takatsu K, Urakaze M et al. 2009 Regulatory mechanisms for adipose tissue M1 and M2 macrophages in diet-induced obese mice. Diabetes 58 2574-2582. (doi:10.2337/db08-1475)

Fujisaka S, Usui I, Kanatani Y, Ikutani M, Takasaki I, Tsuneyama K, Tabuchi Y, Bukhari A, Yamazaki Y, Suzuki H et al. 2011 Telmisartan improves insulin resistance and modulates adipose tissue macrophage polarization in high-fat-fed mice. Endocrinology 152 1789-1799. (doi:10.1210/en.2010-1312)

Hara K, Yamauchi T \& Kadowaki T 2005 Adiponectin: an adipokine linking adipocytes and type 2 diabetes in humans. Current Diabetes Reports 5 136-140. (doi:10.1007/s11892-005-0041-0)

Hemmeryckx B, van Bree R, Van Hoef B, Vercruysse L, Lijnen HR \& Verhaeghe J 2008 Adverse adipose phenotype and hyperinsulinemia in gravid mice deficient in placental growth factor. Endocrinology 149 2176-2183. (doi:10.1210/en.2007-1272)

Hotamisligil GS \& Spiegelman BM 1994 Tumor necrosis factor alpha: a key component of the obesity-diabetes link. Diabetes 43 1271-1278. (doi:10.2337/diabetes.43.11.1271)

Hotamisligil GS, Peraldi P, Budavari A, Ellis R, White MF \& Spiegelman BM 1996 IRS-1-mediated inhibition of insulin receptor tyrosine kinase activity in TNF-alpha- and obesity-induced insulin resistance. Science 271 665-668. (doi:10.1126/science.271.5249.665)

Kanda H, Tateya S, Tamori Y, Kotani K, Hiasa K, Kitazawa R, Kitazawa S, Miyachi H, Maeda S, Egashira K et al. 2006 MCP-1 contributes to macrophage infiltration into adipose tissue, insulin resistance, and hepatic steatosis in obesity. Journal of Clinical Investigation 116 1494-1505. (doi:10.1172/JCI26498)
Kawanishi N, Yano H, Yokogawa Y \& Suzuki K 2010 Exercise training inhibits inflammation in adipose tissue via both suppression of macrophage infiltration and acceleration of phenotypic switching from M1 to M2 macrophages in high-fat-diet-induced obese mice. Exercise Immunology Review 16 105-118.

Kondo E, Sugiyama T, Kusaka H \& Toyoda N 2004 Adiponectin mRNA levels in parametrial adipose tissue and serum adiponectin levels are reduced in mice during late pregnancy. Hormone and Metabolic Research 36 465-469. (doi:10.1055/s-2004-825726)

Kristiansen OP \& Mandrup-Poulsen T 2005 Interleukin-6 and diabetes: the good, the bad, or the indifferent? Diabetes 54 S114-S124. (doi:10. 2337/diabetes.54.suppl_2.S114)

Lumeng CN, Bodzin JL \& Saltiel AR 2007 Obesity induces a phenotypic switch in adipose tissue macrophage polarization. Journal of Clinical Investigation 117 175-184. (doi:10.1172/JCI29881)

Murray PJ 2005 The primary mechanism of the IL-10-regulated antiinflammatory response is to selectively inhibit transcription. PNAS 102 8686-8691. (doi:10.1073/pnas.0500419102)

Okamoto Y, Higashiyama H, Rong JX, McVey MJ, Kinoshita M, Asano S \& Hansen MK 2007 Comparison of mitochondrial and macrophage content between subcutaneous and visceral fat in $\mathrm{db} / \mathrm{db}$ mice. Experimental and Molecular Pathology 83 73-83. (doi:10.1016/j. yexmp.2007.02.007)

Peraldi P, Hotamisligil GS, Buurman WA, White MF \& Spiegelman BM 1996 Tumor necrosis factor (TNF)-alpha inhibits insulin signaling through stimulation of the p55 TNF receptor and activation of sphingomyelinase. Journal of Biological Chemistry 271 13018-13022. (doi:10.1074/jbc.271.22.13018)

Permana PA, Menge C \& Reaven PD 2006 Macrophage-secreted factors induce adipocyte inflammation and insulin resistance. Biochemical and Biophysical Research Communications 341 507-514. (doi:10.1016/ j.bbrc.2006.01.012)

Petry CJ, Evans ML, Wingate DL, Ong KK, Reik W, Constância M \& Dunger DB 2010 Raised late pregnancy glucose concentrations in mice carrying pups with targeted disruption of H19delta13. Diabetes 59 282-286. (doi:10.2337/db09-0757)

Strissel KJ, Stancheva Z, Miyoshi H, Perfield JW II, DeFuria J, Jick Z, Greenberg AS \& Obin MS 2007 Adipocyte death, adipose tissue remodeling, and obesity complications. Diabetes 56 2910-2918. (doi:10.2337/db07-0767)

Suganami T, Nishida J \& Ogawa Y 2005 A paracrine loop between adipocytes and macrophages aggravates inflammatory changes: role of free fatty acids and tumor necrosis factor $\alpha$. Arteriosclerosis, Thrombosis, and Vascular Biology 25 2062-2068. (doi:10.1161/01.ATV. 0000183883.72263.13)

Wang ZV, Schraw TD, Kim JY, Khan T, Rajala MW, Follenzi A \& Scherer PE 2007 Secretion of the adipocyte-specific secretory protein adiponectin critically depends on thiol-mediated protein retention. Molecular and Cellular Biology 27 3716-3731. (doi:10. 1128/MCB.00931-06)

Weisberg SP, McCann D, Desai M, Rosenbaum M, Leibel RL \& Ferrante AW Jr 2003 Obesity is associated with macrophage accumulation in adipose tissue. Journal of Clinical Investigation 112 1796-1808. (doi:10.1172/JCI19246)

Weisberg SP, Hunter D, Huber R, Lemieux J, Slaymaker S, Vaddi K, Charo I, Leibel RL \& Ferante AW Jr 2006 CCR2 modulates inflammatory and metabolic effect of high-fat feeding. Journal of Clinical Investigation 116 115-124. (doi:10.1172/JCI24335)

Xu H, Barnes GT, Yang Q, Tan G, Yang D, Chou CJ, Sole J, Nichols A, Ross JS, Tartaglia LA et al. 2003 Chronic inflammation in fat plays a crucial role in the development of obesity-related insulin resistance. Journal of Clinical Investigation 112 1821-1830. (doi:10.1172/ JCI200319451)

Received in final form 14 June 2011

Accepted 22 June 2011

Made available online as an Accepted Preprint 22 June 2011 